\title{
Understanding Environmental Risk Assessment of GMOs in Africa-The Importance of Regulation and Monitoring
}

\author{
Ademola A Adenle $1,2 *$ \\ ${ }^{1}$ United Nations University Institute of Advanced Studies (UNU-IAS), 6F International Organisations Centre, Pacifico Yokohama, 1-1-1 Minato Mirai Nishi-ku, 220-8502, \\ Yokohama, Japan \\ ${ }^{2}$ National Graduate Institute for Policy Studies (GRIPS), 7-22-1 Roppongi, Minato-ku, Tokyo 106-8677, Japan

\begin{abstract}
Controversy surrounding the use of GMOs and a mixed reaction among the scientific community in Africa has raised several questions as to how risk assessment is done. The environmental risk assessment is a critical regulatory process that has to be carried out before GMOs are released to the farmers and consumers. Due to the limited capacity in Africa to carry out risk assessment based on sound scientific evidence, there is urgent need to encourage easily accessible methods of risk assessment in the face of unfriendly precautionary principle in developing countries including Africa.
\end{abstract}

\section{GMOs and Africa Traditional Heritage}

The fundamental question is- do transgenic or Genetically Modified Organisms (GMOs) pose threat to the environments given all the hullabaloo about GMOs around the world including Africa? The answer to this question is not direct, as one can't say Yes or No to the question. And the reason is simply because no scientific evidence has yet to demonstrate any negative impact of GMOs on the environment [1], although literature evidence in terms of environmental benefit of GMOs has continued to grow [2]. However, anecdotal evidence suggests there may be possible impact of GMOs on the environment, hence the introduction of GMOs into the environment must be preceded by risk assessment, risk management and monitoring.

Against the backdrop of concerns regarding gene flow from GM crop traits, conventional crops have the same pollination characteristics as GM crops, a fact that is often ignored whilst discussing GMOs issues in Africa. For example, the issue of possible contamination of conventional crops called "traditional heritage" by transgenic crops has always come up where I have interviewed the key stakeholders such as scientists and policymakers on GMOs in different African countries. While GMOs are believed to be part of future solutions to agricultural problems in Africa, some of the stakeholders are often concerned about the safety of the GMOs. This is partly due to lack of understanding on GMO issues or biased attitudes towards GMOs. This is why risk assessment of GM crops should encourage comparative evaluation with conventional crops so as to determine the degree of risk before final judgment is passed in favour of one or another. This particular area requires urgent attention as this can form part of an education and awareness process, thereby increasing the understanding of the public and other key stakeholders including farmers, industry, policymakers as well as the scientific community on the risk assessment of GMOs in Africa.

The Cartagena Protocol on Biosafety (CPB) - a supplement of the Convention on Biological Diversity (CBD) was adopted and finalized in Montreal January 2000 [3]. CPB is an international legally-binding treaty that specifically deals with GMO regulation among the countries that are a signatory to the protocol. The precautionary principle is mandated through CPB to control the use and transboundary movement of GMOs. Based on the precautionary principle, a signatory country member can decide on whether to use GMOs or not, particularly when suspected to pose harmful risk in the absence of full scientific evidence. The CPB seeks to protect the biodiversity and ecosystem which billions of poor people in developing countries including Africa depend on from potential risks of GMOs.

\section{Risk Assessment of GMOs}

The risk assessment of GMOs is part of the regulatory process and is followed by risk management and monitoring. This is fundamental to environmental safety given limited understanding on their potential risk to the environment. Therefore it is important to evaluate and understand the levels of inquiry involved in scientific experiments and rigorous environmental risk assessment of GMOs. To perform risk assessment, the GM crops in question are selected and characterized for the risks that may be associated with the products, while all the necessary measures are taken into consideration to mitigate the risks identified through the assessment process that are unacceptable [4] Gene flow, effects on target and non-target organisms, and soil organism biodiversity are among the parameters used for the risk assessment. This usually involves confined field trials of GM crops which are made mandatory to evaluate the potential for harm to the ecosystem. The risk assessment is done on a case-by-case basis to understand the nature and degree of risk posed by the GM crop trait under study. In a layman's explanation, the GM crop is tested for a variety of characteristics, such as to find out whether there is movement of transgenic material (gene flow) from one species to another- conventional plant population. For example, gene flow from GM maize to non-GM maize. Based on the results of the risk assessment, regulators will make decisions on what the nature and level of uncertainty that is acceptable for the approval of the GM crop while taking into account, socio-economic and political aspects.

\section{South Africa- A Leading Example for Environmental Monitoring of GMO Product}

While environmental risk assessment is critical to the release of

*Corresponding author: Ademola A Adenle, Research Fellow, United Nations UniversityInsitute of Advanced Studies (UNU-IAS), Japan, E-mail: adenle@ias.unu.edu

Received April 27, 2012; Accepted April 30, 2012; Published May 04, 2012

Citation: Adenle AA (2012) Understanding Environmental Risk Assessment of GMOs in Africa-The Importance of Regulation and Monitoring. Biosafety 1:e109. doi:10.4172/2167-0331.1000e109

Copyright: (c) 2012 Adenle AA. This is an open-access article distributed unde the terms of the Creative Commons Attribution License, which permits unrestricted use, distribution, and reproduction in any medium, provided the original author and source are credited. 
GMO products [5], only few African countries have sufficient capacity to undertake this assessment. And where capacity building initiatives have taken place many people don't have the opportunity to practice what they have learnt due to lack of regulatory environment. South Africa has the most sophisticated facilities and comprehensive biosafety regulation of GMO products in Africa. South Africa has been growing GM crops for commercialization for over a decade. The only two GM Africa producing countries after South Africa are Burkina Faso and Egypt, although other countries have confined field trials.

The recent relevant example on the development of a monitoring framework for environment impact of GMOs (MON810 Bt maizeinsect resistant trait) was funded through an Environmental Cooperation Programme between South Africa and Norway from 2006 to 2010 [6]. Although, Norway is a non-GM producing country due to its notorious precautionary approach towards GMOs, nevertheless their GenØk (Biosafety Research Unit) facilitated the implementation of the project in South Africa. While one aim of the project was to investigate potential negative interactions between Bt maize and the surrounding environment the results did not identify any significant negative interactions [6], although some issues were identified for subsequent post-market monitoring. This study demonstrates a baseline established for long-term plan development of a comprehensive monitoring system for GMOs, starting from laboratory and glasshouse assessment to field testing.

A similar example is the case of Bt maize (Ajeeb-YG, an instance of introgression of MON810 into a local Egyptian variety with resistance to corn borer pests) in Egypt, but one viewpoint suggests lack of proper environmental risk assessment prior to the release of this GM crop trait in 2008 [7]. Contrary to this viewpoint, a commentary report claims that $\mathrm{Bt}$ maize field trial was intensively carried out in more than 36 locations where maize is cultivated [8]. While this report indicated intensive risk assessment, it was not supported with evidence or detailed analysis for environmental risk assessment. Although, the risk assessment can be done without being made available as public documents (Personal Communication), given the importance of risk assessment in the light of building trust among the public and scientific community, its publication should be encouraged to reinforce the fact that it is part of the GMO regulatory processes before they are released to the farmers and consumers.

Another example is the cultivation of Bt cotton in Burkina Faso where production started since 2008. Prior to the release of Bt cotton, a number of confined field trials and risk assessment was carried out to monitor possible environmental impact of GMO product [9]. This was largely made possible through the assistance of Monsanto and other donors given the limited capacity to undergo environmental risk assessment in this country. Unlike South Africa, cultivation of Bt cotton is rather young, and of course time will tell whether Bt cotton production can be sustainable over the long-term in Burkina Faso.

The argument here is that, there is need for case-by-case understanding of GMO products and the interaction with the environment that can inform regulatory policy-making in Africa. Unfortunately, many African countries suffer from insufficient investment in science and technology [10], and consequently lack scientific and technical information relevant to risk assessment of GMO products. In the absence of first hand experience of case studies that provide better information on how GMOs interact with biodiversity, some scientists can express concern about negative impact that may result from application of GMOs. In fact, the level of concern is even worse among policymakers without a science background due to low level of understanding on GMO issues. There is a difference between empirical evidence and when argument is based on hearsay. It is only through risk assessment based on sound scientific evidence that the recipient country makes decisions, enforceable through biosafety law, to facilitate adoption of GM crops.

\section{Governance of GMOs-Is there a way out?}

Current governance of GMOs in Africa is in a state of disarray and it requires fixing. The use of GMOs remains a sensitive issue among African governments [11], particularly with regards to potential impact of GMOs on the environment and biodiversity coupled with European Union (EU) influence on adoption of GMOs. The tough EU regulation through a highly precautionary approach, the lack of priority on the part of many African governments and capacity building problems among others represent a significant setback for adoption of GMOs in Africa. For example, lack of public biotechnology research and development, largely funded by the governments may explain one of the reasons why few countries in Africa have implemented national biosafety frameworks to adopt GM crops.

Given the lack of sufficient risk assessment expertise, a majority of the African countries don't have a base of scientific expertise in biosafety. Efforts should be directed towards building regional centers of expertise as opposed to the current lack of well coordinated regional organizations in Africa. Instead, regional organizations are currently focusing on policy development without a practical approach towards resolving GMO issues. For example, Kenya has a good range of laboratory facilities with well trained personnel which can act as a regional center of expertise in the Eastern region while Nigeria can serve the same purpose in the Western region given the considerable expertise and relative number of well equipped labs with modern biotechnology including genetic engineering in the country. While harmonizing national regulatory systems within a regional policy framework, this kind of collective effort based on a regional approach can facilitate practical and cost effective risk assessment of GMOs. This approach can largely deal with or partly resolve problems of risk assessment and the high regulatory cost of introducing GMOs which may speed up development of GMOs in Africa coupled with enabling policy environment.

The risk benefit ratio is important and it should be part of decisionmaking process by the regulators although it is currently largely excluded from assessment of GMOs (especially, the EU) [12]. This view is consistent with a recent article that proposes a semi-quantitative riskbenefit analysis methodology as a potential tool that requires limited expertise and facilities and can be useful for GMO risk assessment in developing countries [13]. South Africa is likely to take a lead to demonstrate how this innovative tool can balance risks and benefits of GMOs with a view to facilitating a cost effective risk assessment. Given the potential benefits of this new method, national governments should encourage GMO assessments that will facilitate adoption of this kind of accessible tool for better decision making for the regulators in the light of the controversial precautionary principle.

While the United States Agency for International Development (USAID) and United Nations Environment Program- Global Environment Facility (UNEP-GEF) have previously made efforts to strengthen scientific and technical capacity for regulating GMOs in many African countries, these efforts have yet to lead to meaningful results. Perhaps, it is time to begin to assess the projects and identify why the efforts have not made significant impacts in terms of regulating and adopting GMOs in Africa. This can help in the development of 
Citation: Adenle AA (2012) Understanding Environmental Risk Assessment of GMOs in Africa-The Importance of Regulation and Monitoring. Biosafety 1:e109. doi:10.4172/2167-0331.1000e109

new policies and harmonization with the existing national policy frameworks. However it will require a lot of effort from the national governments and the donors as no results will be achieved without external funding which must be well prioritized.

\section{Acknowledgment}

I would like to thank the Japan Society for Promotion of Science for the support. Grateful thanks to Jane Morris for helpful review and valuable comments.

\section{References}

1. Sanvido O, Romeis J, Bigler F (2007) Ecological impacts of genetically modified crops: ten years of field research and commercial cultivation. Adv Biochem Eng Biotechnol 107: 235-278.

2. Carpenter JE (2011) Impacts of GM crops on biodiversity. GM Crops 2: 7-23.

3. (2000) Convention on Biological Diversity (CBD):Cartagena Protocol on Biosafety to the Convention on Biological Diversity: text and annexes. Montreal: Secretariat of the Convention on Biological Diversity.

4. Hilbeck A, Meier M, Rombke J, Jansch S, Teichmann H, et al. (2011) Environmental risk assessment of genetically modified plants - concepts and controversies. Environmental Sciences Europe 23: 13
5. (2010) African Centre for Biosafety (ACB). The monitoring of enviromental impacts of GMOs in South Africa: a status quo report.

6. (2011) Department of Environmental Affairs (DEA). Montoring the Enviromenta Impacts of GM maize in South Africa.

7. Sawahel W (2008) Egypt approves commercialisation of first GM crop. Scidev Net.

8. Abdallah N (2010) GM crops in Africa:Challenges in Egypt. GM Crops 1: 116-119

9. Vitale J, Ouattarra M, Vognan G, (2011) Enhancing Sustainability of Cotton Productions Systems in West Africa: A Summary of Emperical Evidence from Burkina Faso. Sustainability 3: 1136-1169.

10. Morris EJ (2011) Modern Biotechnology-Potential Contribution and Challenges for Sustainable Food Production in Sub-Saharan Africa. Sustainability 3: 809822

11. Adenle AA (2011) Response to issues on GM agriculture in Africa: Are transgenic crops safe? BMC Research Notes 4: 388.

12. McHughen A (2012) Introduction to the GM crops special issue on biosafety food and GM regulation. GM crops and Food: Biotechnology in Agriculture and the Food Chain 3: 6-8.

13. Morris EJ (2011) A semi-quantitative approach to GMO risk-benefit analysis. Transgenic Res 20: 1055-1071. 